\title{
Environmental pollution and arthropod community change: Impact of quarry activities on invertebrate biodiversity in Ghana.
}

\author{
Sampson Addae ${ }^{1}$, Danilo Harms ${ }^{2}$, Michael Osae ${ }^{3}$, Roger Sigismund Anderson ${ }^{1}$, Jones \\ Quartey $^{1}$, Ben Aikins ${ }^{1}$, and Sampson Addae ${ }^{1}$ \\ ${ }^{1}$ University of Ghana \\ ${ }^{2}$ Universität Hamburg \\ ${ }^{3}$ Biotechnology and Nuclear Agriculture Research Institute, Ghana Atomic Energy \\ Commission.
}

February 17, 2021

\begin{abstract}
Quarry operations can have a negative impact on invertebrate biodiversity and threaten local species through a variety of factors, such as habitat loss and pollution. Quarrying is a common practice in Ghana, but little is known about its effects on local insect diversity and abundance. In this study, the relationship between quarry operations and insect communities on an active quarry site, the Mowire quarry site in the Ashanti region of Ghana was assessed. Transect counts, aerial nets, pitfall traps, Flight interception traps (FIT) and fruit baiting (Charaxes) traps were employed to assess arthropod assemblage, specifically insects as a surrogate for arthropod communities. A total of 2,902 individual insects belonging to 56 families and eleven orders were recorded in all transect points across the three sampling zones. Quarry operations had little impact on the relative abundance $(\mathrm{N}=974)$ of insects at Transect point $(\mathrm{TP}) 400 \mathrm{~m}$ in the Eastern Zone (EZ), species richness $(\mathrm{S}=49)$ and the highest abundance $(\mathrm{N}=302)$ corresponding with high diversity of flowering plants at this site that are a food source for pollinators and herbivorous insects. Quarry operations negatively affected the relative abundance $(\mathrm{N}=541)$ and richness $(\mathrm{S}=$ 37) of insects in the Western zone (WZ), significantly affecting TP 400m in the WZ, corresponding to the low abundance of food plant as well as volumes of dust that settle at the WZ after every blast, as dust travels in the direction of this zone. It is recommended that interventions to prevent biodiversity habitat loss in and around the quarry operational site should focus on policies that ensure and enforce the establishment of a dust control mechanism system in the extractive industry.
\end{abstract}

\section{Hosted file}

Manuscript final.pdf available at https://authorea.com/users/378584/articles/509571environmental-pollution-and-arthropod-community-change-impact-of-quarry-activitieson-invertebrate-biodiversity-in-ghana 